\title{
A Study of the K Drought Monitoring Model
}

\author{
Jinsong Wang, ${ }^{1,2}$, Suping Wang', Yiping Li ${ }^{1 *}$, Wenping $\mathrm{He}^{2}$, \\ Xiaoyun Liu', Yulong Ren ${ }^{1}$ \\ ${ }^{1}$ Institute of Arid Meteorology of China Meteorological Administration; Key Laboratory of Arid Climatic Change \\ and Disaster Reduction, China Meteorological Administration; Key Laboratory of Arid Climatic Change \\ and Reducing Disaster of Gansu Province, \\ 2070 Donggang East Rd., Lanzhou 730020, China \\ ${ }^{2}$ National Climate Center, China Meteorological Administration, \\ 46 Zhongguancun South Rd., Beijing 100081, China
}

Received: 14 April 2017

Accepted: 15 June 2017

\begin{abstract}
This study established a $\mathrm{K}$ drought monitoring model to determinate the start, duration, and strength of drought. Based on 586 meteorological stations' conventional observation data in China from 1961 to 2015, we calculated the elements and parameters needed to structure the model. Because soil has a memory of its antecedent moisture change, the drought intensity of a day is determined by the moisture content of the day and earlier days. Furthermore, the change of moisture content depends not only on precipitation but also on the temperature associated with evaporation. In order to consider the impact of previous precipitation and evaporation on the present drought, we made a cumulative treatment of previous precipitation and reference evapotranspiration. However, the influence degree of the antecedent precipitation and reference evapotranspiration on soil moisture is weakened closer to the present day. This means that the contribution of the precipitation and reference evapotranspiration in earlier days to present soil moisture decays over time. After comparison between the exponential decay form and the linear decay form of the previous precipitation and reference evapotranspiration, the scheme of linear decay form is selected. Then, a K drought monitoring model was established to consider the antecedent precipitation and reference evapotranspiration accumulation and their decay influence. The proposed $\mathrm{K}$ drought monitoring model can be used to evaluate the timing of drought onset, evolution process, and severity.
\end{abstract}

Keywords: drought, precipitation, reference evapotranspiration, $\mathrm{K}$ drought monitoring model

\section{Introduction}

Drought is a common occurrence in the world and can occur anywhere. Losses caused by meteorological disasters - especially droughts - have been increasing of late and, consequently, seriously threaten the sustainable

*e-mail: liyiping532@163.com development of the social economy and environment worldwide [1-2]. China is one of the countries with the most serious meteorological disasters in the world. For China as a whole, the losses of meteorological disasters account for more than $70 \%$ of total losses of all natural disasters. Also, drought disasters account for more than $50 \%$ of meteorological disasters in China. So among natural disasters, drought has the most affected area and can result in the most serious losses in China - especially 
in agricultural production [3]. Zhai et al. [4] pointed out that the most severe droughts that covered large areas mainly occurred in northern and western China during the mid-to-late $20^{\text {th }}$ century; however, they were located in southwestern China in the early $21^{\text {st }}$ century. According to the released data from the Bulletin of Flood and Drought Disasters in China, the average annual affected agricultural area and the annual loss of grain resulting from drought from 1950 to 2007 are 21.7 million hectares and 15 billion 800 million $\mathrm{kg}$, respectively. Taking an extra-seasonal (from autumn to spring) serious drought for the period 2010-11 occurred in the middle and lower reaches of the Yangtze River as an example, and the direct economic losses resulting from this drought disaster reached RMB 14.94 billion. It also caused difficulty for drinking water involving 4.236 million people and 1.07 million livestock.

Under the background of global warming, drought has shown a trend of stronger intensity, higher frequency, and wider range in the world [5-7]. Drought may become more severe and widespread, and also a threat to crops that compromises food production capacity and food security [8]. Droughts can be especially devastating since reduced agricultural productivity may raise serious food security and other public health concerns in developing countries. However, the impact of today's droughts both in Central Europe and globally are more complex and often also affect many other sectors besides agriculture. Most notable are drought impacts on transportation, energy production, tourism and recreation, ecosystem services, and health, as well as broader environmental and social impacts [9]. Facing this serious drought situation, the monitoring and early warning of drought is very necessary both in scientific research and to decision-makers. A global drought early warning system (GDEWS) has been constructed to reduce vulnerability to a natural hazard by providing users such as relief agencies or national authorities the maximum possible lead time to put mitigation strategies into place [10]. Undoubtedly, people have been exploring effective ways to achieve the purpose for drought monitoring and early warning.

Reviewing the research development of drought monitoring and early warning, it can be found that one of the most effective ways to monitor and quantify the areal extent and severity of drought is to use a drought monitoring model (called drought index). Jason et al. [11] pointed out that the drought indices are a useful component of drought warning systems. Different drought indices have been developed and applied for drought monitoring [12]. At present, no fewer than 100 kinds of drought monitoring index have been proposed to quantitatively characterize drought. The most well-known drought monitoring model is the Palmer drought severity index (PDSI), which has been called a milestone in drought monitoring. According to the results of research and taking the widely used drought indices as an example, the drought monitoring models or drought indices are usually divided into three categories:
1. Considering precipitation only, e.g., the standard precipitation index (SPI) [13-14], the precipitation anomaly (Pa) [15], the Munger index [16], and the Blumenstock index [17].

2. Considering the difference between precipitation and evaporation, such as the standardized precipitation evapotranspiration index (SPEI) [18], drought index $\mathrm{H}$ [19], drought index DRI [20], and the composite drought index (CI) [21].

3. Considering surface water balance, e.g., the Palmer drought severity index (PDSI) [22].

However, it is well known that drought in an area depends not only on precipitation, but also temperature. So a drought monitoring model or a drought index, which only considers precipitation alone (for example the first category of the index mentioned above), is not comprehensive. The second type of index mentioned above, which is defined by the difference between precipitation and evaporation, has its advantages compared with the drought index defined by precipitation alone, but there are still shortcomings. As far as index $\mathrm{H}$ [19] is concerned, if $\mathrm{H}$ is less than 0 , from its definition that means the amount of precipitation cannot meet the needs of evaporation in the average state, and the climate is dry. So these kinds of drought indices are suitable for determining a regional long-term climate dry or wet state, but this state is different from drought conditions. Namely, drought refers to a temporary period relatively short in precipitation, but the climate dry state refers to a period permanently short in precipitation. Drought can occur everywhere, whether the area is arid or humid; but the climate dry state exists only in an arid climatic zone. The major limitation of the SPEI is that it can only be used to determine the drought on a monthly scale or longer. The SPEI cannot be used to measure drought for less than a week. For the CI, in the process of daily drought monitoring, the phenomenon of uncontinuous enhancement of drought (UED) appeared due to the assumption that the daily precipitation of the previous 30 and 90 days carried equal weight to the contribution to drought development [23]. The PDSI is a well-known index to monitor drought and it also takes into account the effects of precipitation and evapotranspiration on drought. But the PDSI requires soil moisture data to join the index calculation, and actually most stations lack the soil moisture data in the present condition. So the PDSI is difficult to apply to real-time operation applications due to the shortness of soil moisture data [24].

Therefore, based on the above previous studies and in view of the deficiency of the existing drought indices, this study aims to establish a drought monitoring model, constructed not only by precipitation but also by evapotranspiration. In the meantime, it is important to consider the accumulation and attenuation effects of precipitation and evapotranspiration on drought for improved understanding of the process of drought occurrence, development, and relief. In other words, we must develop such a drought monitoring model in this study to measure the daily drought extent affected 
by precipitation and evapotranspiration with the aim to determine the timing and strength of a drought.

Drought is an extreme climate event that consists of climatic uncertainties induced by the environment. Thus, the threshold of drought onset as well as the thresholds of different drought severity levels, which are expressed by the drought indices, will necessarily involve the extreme value theory. Zhang et al. [25-28] have carried out a large number of theoretical works and practical applications in the aspect of the extreme value model. Some types of extreme value distributions and the corresponding basic formulas were given in these literatures. Take the generalized extreme value (GEV) distribution as an example; a drought index based on the GEV distribution was used in our past works [29-30]. But the drought index defined in this paper and its thresholds of drought severity levels are divided according to the percentile method following the approach of Svoboda et al. [31]. And this is also a conventional method in the drought grade division.

\section{Study Area and Data}

The study area in this paper is mainland China and Hainan Island. In this study area, 586 observation stations were selected (Fig. 1).

Climate data used in this work - daily precipitation, daily maximum and minimum temperatures, sunshine hours, relative humidity, and average wind speed from 1961 to 2015 - are provided by the National Meteorological Information Centre (NMIC) of the Chinese Meteorological Administration (CMA), and have passed quality control.

\section{Construction of the Drought Monitoring Model}

\section{The Basic Idea}

The occurrence of drought is determined by the shortage of precipitation and the rise of temperature. So the extent of drought depends on the precipitation reduction and temperature increase degrees. But there is a concept we must make clear: that the occurrence of drought is a relative slow development process rather than an instantaneous event. If there is no precipitation in the present day, drought may not happen immediately. Of course, if there is no precipitation for a long time, drought may happen one day. The key problem is to look for the date of the "one day" - namely the start date of the drought occurrence. Then it is necessary to clarify the mechanism of the effects of precipitation accumulation and attenuation in previous periods on recent drought. In order to obtain this understanding, we have carried out relevant research and have found that most droughts are caused by a precipitation deficit within three months [32]. Among these study samples, $50 \%$ of droughts were caused by a one-month (30 days) deficit in precipitation. A deficit of three months (90 days) in precipitation accounted for $30 \%$ of the droughts, and that caused by deficit over three months (usually five months, i.e. 150 days) in precipitation is less than $20 \%$. The above results reveal that the state from precipitation deficit to drought-forming needs to go through a changing process that is related to soil moisture. This is the inherent decay mechanism of the soil-land surface system, which is caused by the demands of the water balance [33]. These

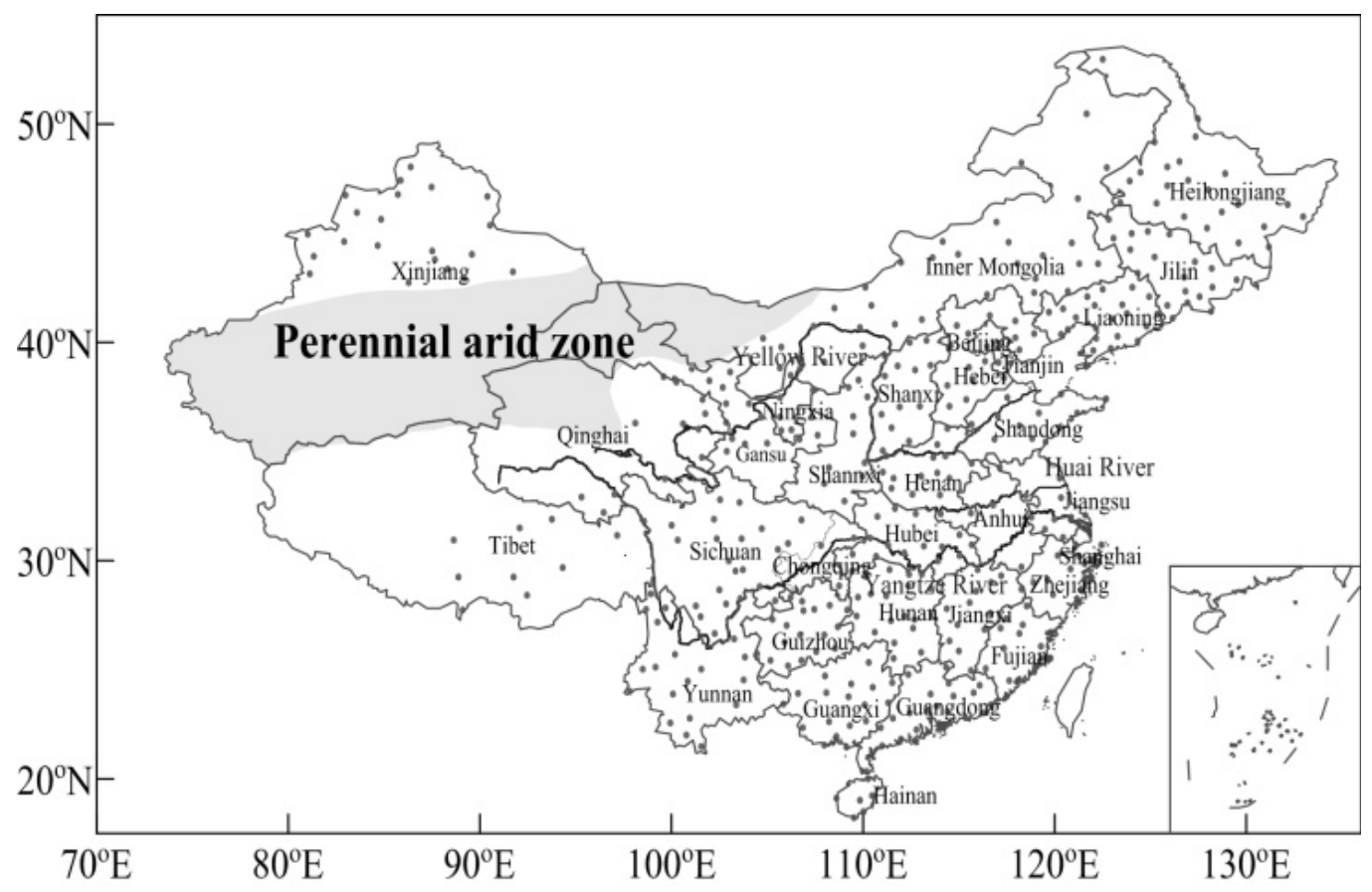

Fig. 1. Spatial distribution of observation stations used in this study (dots) and the names of different provinces that are mentioned in the text below; blue lines denote locations of the Yangtze, Huai, and Yellow rivers. 
demands are related to the accumulation and attenuation of precipitation and evapotranspiration.

\section{The Construction Process of the Model}

Based on the above basic ideas, a simple physical drought-monitoring model is constructed and involved in the contribution of precipitation and evapotranspiration to the formation of drought.

Here we call this model as $\mathrm{K}$ drought monitoring model, it can be expressed as

$$
K=P^{\prime} / E^{\prime}
$$

...where $K$ represents the daily drought monitoring index value calculated from the model by using the daily data of observation stations, and $P^{\prime}$ and $E^{\prime}$ are the relatively variable rates of precipitation and reference evapotranspiration, respectively.

The $P^{\prime}$ is given by

$$
P^{\prime}=P / \bar{P}
$$

...where $P$ is the cumulative precipitation of any given day, $\bar{P}$ is the latest 30 -year average amount of precipitation (i.e. climate normal) corresponding to the above given day. The data of $P$ is obtained from the observation stations.

$E^{\prime}$ is given by

$$
E^{\prime}=E / \bar{E}
$$

...where $E$ is the cumulative reference evapotranspiration of any given day (the same day as that of $P$ ), and $\bar{E}$ is the latest 30-year average amount of reference evapotranspiration (i.e., climate normal) corresponding to the above-given day. In this paper, $E$ is calculated by using the FAO Penman-Monteith method [34].

Using the daily meteorological data, the cumulative precipitation and reference evapotranspiration at a certain number of days prior to the present day can be calculated. The question is how to determine the number of days prior to the present day of the meteorological factors that continue to affect drought and how to consider their decay types. From the understanding of section the Basic Idea, we can select 30, 90, and 150 days as the number of days prior to the present day to represent the meteorological factors that continue to affect drought within one, three, and five months, respectively. Usually, there are two types of decay modes, i.e., exponential and the linear types. In the study by $\mathrm{Lu}$ [33], the exponential decay mode was considered when the influence of previous precipitation on drought was analyzed. Here, a comparison of the two decay modes is given in order to select the better one. The linear decay mode can be expressed as follows:

$$
P=\sum_{n=0}^{N}(a n+b) P_{n}
$$

$$
E=\sum_{n=0}^{N}(a n+b) E_{n}
$$

The exponential decay mode can be expressed as follows:

$$
\begin{aligned}
& P=\sum_{n=0}^{N} c^{n} P_{n} \\
& E=\sum_{n=0}^{N} c^{n} E_{n}
\end{aligned}
$$

...where $n$ is the number of the day prior to the present day; $N$ is the number of earlier days from the present day (which can be determined as $N=30, N=90$, or $N=150$, respectively, according to the considered time length of precipitation and evapotranspiration cumulative and attenuation); $P$ and $E$ are the same as in Equations (2) and (3); $P_{n}$ and $E_{n}$ are the precipitation and reference evapotranspiration of day $n$, respectively; $a, b$, and $c$ are the parameters, where $a$ and $b$ are the slope and the vertical intercept of the linear decay mode, respectively, and $c$ is the horizontal intercept (tend to be zero) of the exponential decay mode.

Fig. 2 shows the different contribution rates of precipitation and evapotranspiration to drought under two kinds of decay models and different $N$. It is clear that at the same contribution rate and with the same $N$, the number of days from the present day is different under the different modes. This means that the contribution of the precipitation and evapotranspiration cumulative timescale to drought under different attenuation modes is different. In the specific application, the major issue is how to select the $N$ and decay modes.

As far as $N$ is concerned, here taking it as 90 according to the existing research results, which pointed out that more than $80 \%$ of droughts were caused by a three-months (90-day) deficit in precipitation [32]. Selecting $N$ as 90 can ensure that the memory time effect of precipitation in the soil is fully considered in the majority (account for $80 \%$ ) of the drought events.

For the choice of mode, namely which attenuation mode can describe the contribution of precipitation attenuation to drought better, we will discuss this issue in the next section.

\section{Comparison between the Two Decay Modes}

With taking $N$ as 90 , we obtained the daily values of the $K$ drought index that have considered precipitation and reference evapotranspiration of the previous 90 days from the present day. The daily values of the $K$ drought 


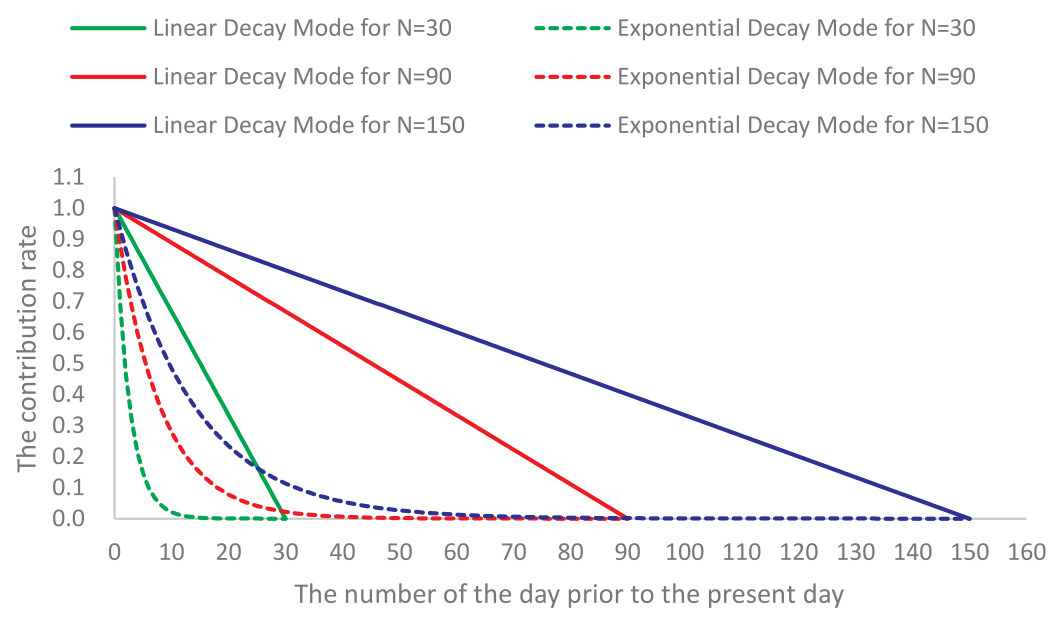

Fig. 2. Contribution rates of precipitation and evapotranspiration to drought with the $N$ (number of earlier days from the present day) being 30, 90, and 150 days for two kinds of decay modes.

index for considering linear decay mode can be obtained from Equations (4) and (5). The daily values of the $K$ drought index for considering exponential decay mode can be obtained from Equations (6) and (7).

A good drought index should not only be able to accurately monitor the extent and strength of drought (i.e., the spatial variability of drought at a span of time), but also to accurately characterize the whole process of drought start, development, duration, mitigation, and release (i.e., the temporal variability of drought at a place). For the different decay forms of the index, which one is more able to indicate the temporal variation of drought will be determined in the following way.

It is well known that a rare severe drought disaster occurred from autumn 2009 to spring 2010 in southwestern China. During this period precipitation in the region was not even $200 \mathrm{~mm}$ - less than half of that in normal years. The scope of the drought reached Yunnan, Guizhou, Guangxi, and Sichuan provinces. This drought had a strong impact on agriculture and life in the region. According to the statistics of the Civil Affairs Department, the number of drought-affected people reached 61.3 million, the affected area of crops was 5.03 million $\mathrm{hm}^{2}$, and the direct economic loss was 23.6 billion yuan.

In 2011 a serious spring drought occurred in Jiangsu, Zhejiang, Anhui, Hubei, Hunan, and Jiangxi provinces and in the city of Shanghai in the middle and lower reaches of the Yangtze River. According to incomplete statistics [35], the affected area of crops was 12.2 million $\mathrm{hm}^{2}$ in Jiangsu, Anhui, Hubei, Hunan, and Jiangxi provinces, and the direct economic loss was 5.4 billion yuan in Jiangsu and Anhui provinces alone.

These two drought events were selected as examples to be analyzed in this paper. For simplicity, selecting Xingren of Guizhou provinces as the representative station in the drought occurred from autumn 2009 to early spring 2010, and selecting Macheng of Hubei provinces as the representative station in the drought occurred from the winter to spring 2011. Here it should be noted that the seasons for a year are divided according to the definition of climatic season, i.e., from December last year to February in this year as defined as winter, from March to May as defined as spring, from June to August as defined as summer, and from September to November as defined as autumn. Fig. 3 shows the evolution of the daily K-index values in drought monitoring based on two different attenuation modes and the accompanying daily precipitation. The detail categories of drought severity (threshold levels) about $\mathrm{K}$ index refer to literature [36], from the definition of $\mathrm{K}$ index, the smaller the value of $\mathrm{K}$, the more severe the degree of drought. In Fig. 3 it shows clearly that the different modes influence much the detections of the drought. For the daily value of $\mathrm{K}$ drought index with exponential decay mode, the most obvious feature is the jagged change of the daily value with the up-and-down fluctuations. Combined with change of daily precipitation to analyze, the change of index is more sensitive to that of precipitation. But for the daily value of $\mathrm{K}$ drought index with linear decay mode, the change of the daily value is relatively flat.

This means that the $\mathrm{K}$ drought index based on the linear decay model is better to reflect the development process of drought than that based on the exponential decay pattern, because the process of drought occurrence is a slowly changing process and its extent is gradually increased. Namely, its evolution is an experience from no drought, to incipient drought, to moderate drought, and then to severe drought - rather than a sudden present direct from incipient to severe drought. In the case of drought relief, when a small amount of precipitation occurs, the degree of drought relief is not obvious, and only a large amount of precipitation may alleviate drought. From Fig. 3 we can see that the $\mathrm{K}$ drought index based on linear decay can reflect the slow accumulation process of drought occurrence and development, and also can reflect the effect of precipitation amount on drought mitigation, while the $\mathrm{K}$ drought index based on exponential decay cannot reflect these characteristics. 

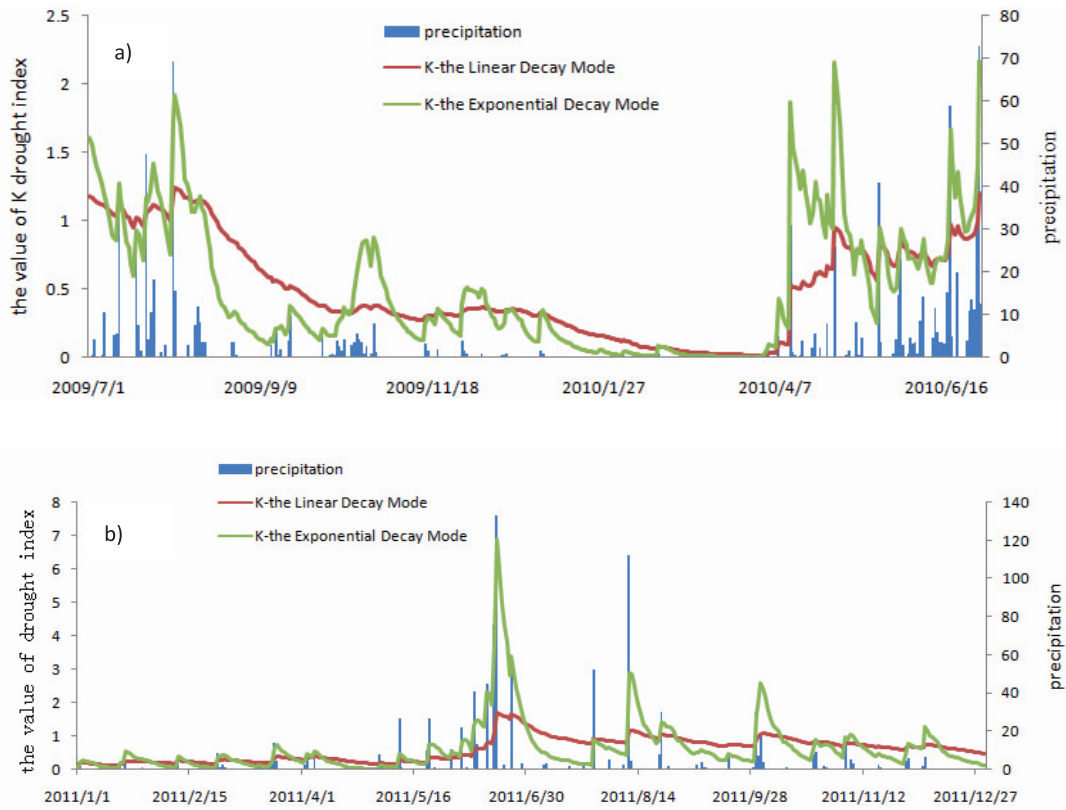

Fig. 3. Change of the daily K-index values under two different attenuation modes and the observed daily precipitation a) Xingren Station in Guizhou Province b) Macheng Station in Hubei Province (the smaller the value of K, the more severe the degree of drought).

\section{Application of the $K$ Drought Index Based on Linear Decay}

We previously tested the ability of $K$ drought index to describe characteristic of the drought process with two representative stations for two drought events. The final results show that the $K$ drought index based on linear attenuation can better characterize the drought process. So in this Section, we are still selecting the same two drought events, and here to test the ability of $K$ drought index (based on linear attenuation) to monitor the drought intensity and extent.

A very serious drought occurred from autumn 2009 to spring 2010 in southwestern China due to the abnormal low precipitation and high temperature in this area. Fig. 4 presents the monitoring results of drought extent and strength of autumn 2009 to spring 2010 by use of the K index. Since Oct. 2009, most areas of

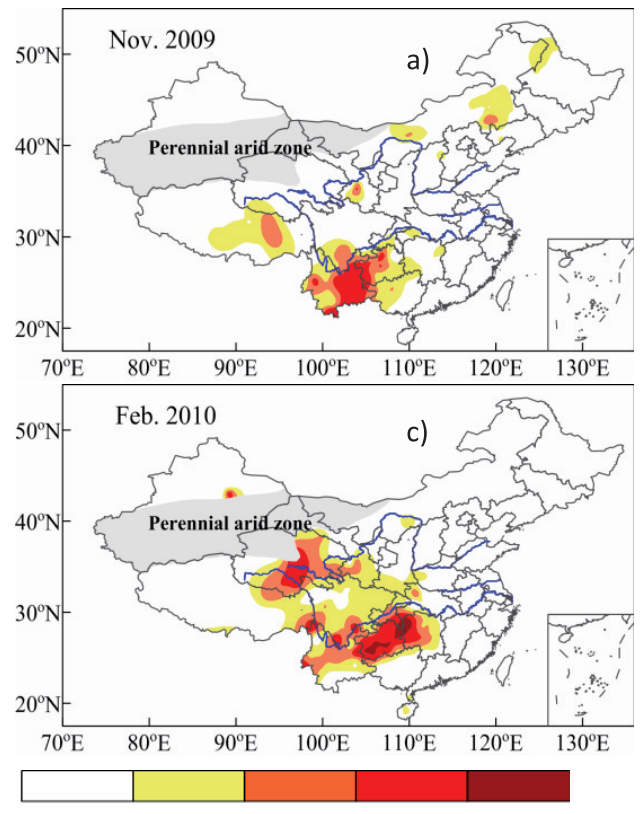

No drought Incipient Moderate Severe Extreme
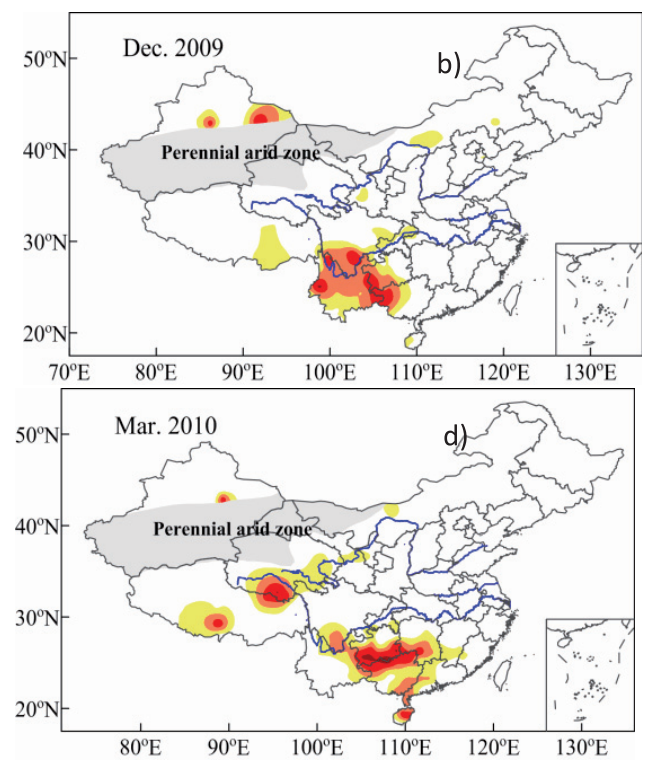

Fig. 4. Monitoring of drought spatial extent and severity by index K in southwestern China from autumn 2009 to spring 2010 at different months: a) November 2009, b) December 2009, c) February 2010, and d) March 2010. 

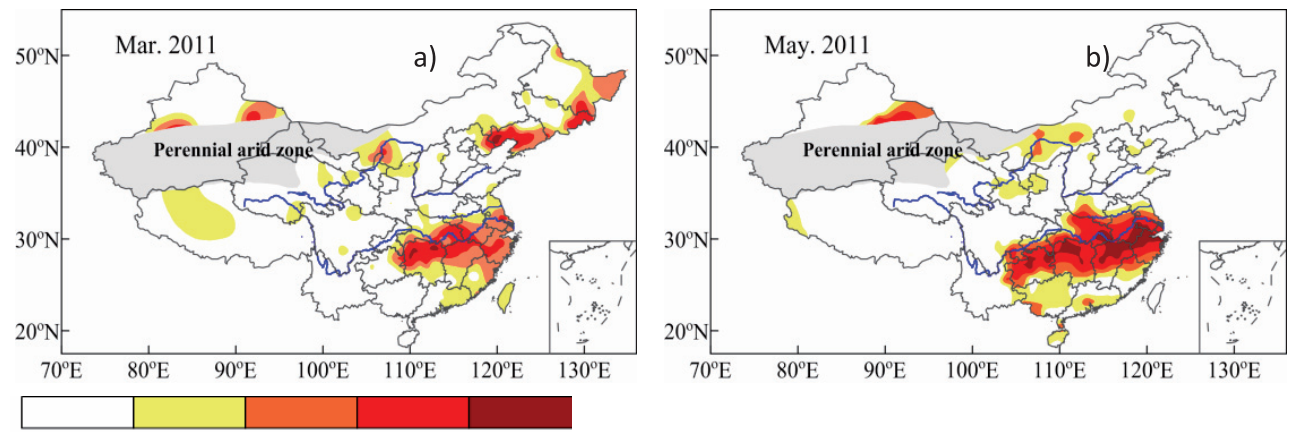

No drought Incipient Moderate Severe Extreme

Fig. 5. Monitoring of drought spatial extent and severity by index $\mathrm{K}$ in middle and lower reaches of the Yangtze and the Huai river basins in spring 2011 at different months: a) March 2011 and b) May 2011.

Yunnan Province appeared to have less precipitation and higher temperatures. In November and December 2009 an obvious drought occurred across most of Yunnan (Figs 4a-b). In January 2010 the intensity and extent of the drought were essentially constant (not shown). In February 2010 the scope of drought stretched to the east to Guizhou, eastern Hunan, and northern Guangxi provinces, and at this stage drought intensity reached the strongest degree (Fig. 4c). In March 2010 the scope and intensity of the drought weakened (Fig. 4d). The drought ended in April 2010 (not shown).

Fig. 5 shows the monitoring results of drought extent and strength in spring 2011 by use of the $\mathrm{K}$ index. In March 2011 the drought was located in the middle and lower reaches of the Yangtze River and south of the Huai River (Fig. 5a).The more serious drought occurred in northern Hunan Province. Based on the data from the Impact Assessment of Spring Climate of Hunan Province, in the most serious drought period the droughtaffected area in this province was 9 million hectares, and 0.11 million people and 0.42 million large livestock encountered drinking water difficulties. In April 2011 drought intensity continued to develop in most of the middle and lower reaches of the Yangtze and Huai. An especially heavy drought struck northern Hubei, Anhui, western Jiangsu, and southwestern Hunan provinces (not shown). In May 2011 drought intensity increased in northern Hunan, northern Jiangxi, northern Zhejiang, and southern Jiangsu provinces, and at the junction of Anhui and Hubei provinces (Fig. 5b). The $\mathrm{K}$ drought index can well reproduce these drought characteristics.

\section{Conclusions and Discussion}

The drought of an area depends not only on a change of precipitation, but also on a change in temperature. To meet the above conditions, an index can to monitor drought was constructed in this paper - the $K$ drought index - by taking into account both precipitation and temperature simultaneously. So from the construction process of the $K$ drought monitoring model we can understand that the
$K$ drought index calculated from the model had a clear physical meaning. The $K$ drought index is currently taken as a linear attenuation form of precipitation and evapotranspiration; this means that the days before the present day within the period of the scale are treated unequally with the contribution of precipitation and evapotranspiration to the drought. For the requirement of operational monitoring, a drought index should be able to measure the daily drought extent so that it can determine the start, duration, and strength of the drought event. We showed previously that the $K$ drought index can meet the above requirements. Therefore, the index can be used to monitor drought and to analyze the spatial and temporal variability of drought extent and strength. It also has the following advantages:

- It considers the dominant factors of the affecting drought: precipitation and evapotranspiration.

- It catches the water budget.

- Multi-region adaptability as the subregion defines drought level thresholds.

- Multi-time scale adaptability - monthly scale, day scale.

- Easily calculated.

Of course, any drought model has its advantages and disadvantages and the $K$ drought model is no exception. In this paper, the monitoring accuracy of the $K$ model was discussed, and its error analysis can refer to our previous works [29, 37].

The purpose of this paper is to provide a drought index with clear physical meaning, easy access to data and simple calculation, and the capability of day-to-day monitoring of the start, duration, and intensity of drought. Through the above analysis of some examples in this paper, the purpose has been achieved. However, we can see that the drought index here is more reflected in the meteorological drought situation. But in fact, how does the meteorological drought affect crops and how long of a time and how much is the degree of impact? These problems are also worthy of further study. So, in order to provide more suitable means for the practical application and better suggestions to decision-makers, considering the different crops and their different 
growth periods in different regions is necessary for this drought monitoring model. These needs will continue to be studied in the next step.

\section{Acknowledgements}

Our research was supported by project GYHY (QX) 201506001-5 and 973 Program 2013CB430206 from the Ministry of Science and Technology of China, and also by the operational project of the Institute of Arid Meteorology. Jin-Song Wang, one of the authors, a visiting scientist at the National Climate Center of the Chinese Meteorological Administration, would like to express great appreciation for the working conditions and convenience provided by the center. We are thankful to Dr. Michael Hayes of the U.S. National Drought Mitigation Center for his collaboration. We are also thankful to Prof. Zhou Guangsheng of the Chinese Academy of Meteorological Sciences and Prof. Zhang Qiang of the Gansu Provincial Meteorology Bureau for their constructive comments. We also thank the reviewers and editors for helpful comments and suggestions that improved the manuscript.

\section{References}

1. WILHITE D.A. Drought as A Natural Hazard: Concepts and Definitions. In: WILHITE D.A., (eds) Drought: A Global Assessment, London: Routledge, 3, 2000.

2. WANG J.S., LI Y.H., WANG R.Y., FENG J.Y., ZHAO Y.X. Preliminary analysis on the demand and review of progress in the field of drought meteorological research. Journal of Arid Meteorology. 30 (4), 497, 2012 [In Chinese].

3. ZHANG Q., CHEN L.H., WANG R.Y., XIAO G.J., LI Y., DENG Z.Y., WANG H.L., ZHAO H. Climate change and food, food safety in Northwest China. Journal of Arid Meteorology. 30 (4), 509, 2012 [In Chinese].

4. ZHAI J.Q., HUANG J.L., SU B.D., CAO L.G., WANG Y.J., JIANG T., FISCHER T. Intensity-area-duration analysis of droughts in China 1960-2013. Climate Dynamic. 48 (1), 151, 2017

5. DAI A.G. Drought under global warming: a review. Wiley Interdisciplinary Reviews: Climate Change. 2, 45, 2011.

6. DAI A.G. Increasing drought under global warming in observations and models. Nature Climate Change. 3, 52, 2013.

7. DAI A.G., ZHAO T.B. Uncertainties in historical changes and future projections of drought. Part I: Estimates of historical drought changes. Climatic Change. 2016, DOI: 10.1007/s10584-016-1705-2.

8. MA X., WU S.H., LI Y.E., ZHANG X.Y., GAO Q.Z.; WU Y. Rice re-cultivation in southern China: An option for enhanced climate change resilience in rice Production. J. Geogr. Sci. 23 (1), 67, 2013.

9. WILHITE D.A. Managing drought risk in a changing climate. Climate Research. 70, 99, 2016.

10. WILL P., JUSTIN S., ROBERT S., DOUGLAS C., ROGER P., JÜRGEN V.V., RICHARD R.H.J., MICHAEL J. B., MARK S., ROGIER W., ALBERT I.J.M.V.D., BENJAMIN L.H., FLORIAN P., MICHA W., EMANUEL D., FREDRIK W., WOLFGANG W., SIEGFRIED S., KINGTSE M.,
MARGARET N., LYNETTE B., LILIANA N., RENS V.B., MARC B., LUIS G.G..D.G., JOÃO G.Z.D.M., RICHARD L. Toward global drought early warning capability: Expanding international cooperation for the development of a framework for monitoring and forecasting. Bulletin of American Meteorological Society. 776, 2013.

11. JASON A.O., MARTHA C.A., CHRISTOPHER H., MARK S. Using temporal changes in drought indices to generate probabilistic drought intensification forecasts. Journal of Hyrometeorology. 16, 88, 2015.

12. HAO Z.C., AGHA KOUCHAK A. A nonparametric multivariate multi-index drought monitoring framework. Journal of Hyrometeorology. 15, 89, 2014.

13. MCKEE T., DOESKEN N., KLEIST J. The relationship of drought frequency and duration to time scales. Preprints, 8th Conference on Applied Climatology, 17-22 January. Anaheim, California, 1993.

14. HAYES M., SVOBODA M., WALL, N., WIDHALM M. The Lincoln Declaration on drought indices: Universal meteorological drought index recommended. Bull. Am. Meteorol. Soc. 92, 485, 2011.

15. HENRY A.J. Climatology of the United States. Bulletin Q: Weather Bureau Bull. Washington, D C, U.S., 51, 1906.

16. MUNGER T.T. Graphic method of representing and comparing drought intensities. Mon. Wea. Rev. 44, 642, 1916.

17. BLUMENSTOCK G. Drought in the United States analyzed by means of the theory of probability. Washington, D.C.: United States Dept. of agriculture, Technical Bulletin. 1942.

18. VICENTE-SERRANO S.M., BEGUERIA S., LOPEZMORENO J.I. A multi-scalar drought index sensitive to global warming: The standardized precipitation evapotranspiration index - SPEI. J. Climate. 23, 1696, 2010.

19. MA Z.G., HUANG G., GAN W.Q., CHEN M.L. MultiScale temporal characteristics of the dryness/ wetness over northern China during the last century. Chinese Journal of Atmospheric Sciences. 29, 671, 2005 [In Chinese].

20. WANG J.S., CHEN F.H., JIN L.Y., BAI H.Z. Characteristics of the dry/wet trend over arid central Asia over the past 100 years. Climate Research.41, 51, 2010.

21. ZHANG Q., ZOU X.K., XIAO F.J., LV H.Q., LIU H.B., ZHU C.H., AN S.Q. Classification of meteorological drought. GB/T 20481, People's Republic of China national standard. Beijing: China Standard Press, pp, 17, 2006, [In Chinese].

22. PALMER W. Meteorological drought. Weather Bureau Research Paper 45, U.S. Department of Commerce, Washington, DC, 58, 1965.

23. ZHAO H.Y., HOU M.T., LIU W.P., MA Y.L. Application of drought index in daily monitoring in Shanxi. Journal of Arid Meteorology. 32 (4), 505, 2014 [In Chinese]

24. ZHAO H.Y., GAO G., ZHANG P.Q., YAN X.D. The modification of meteorological drought composite index and its application in southwest China. Journal of Applied Meteorological Science. 22 (6), 698, 2011 [In Chinese].

25. ZHANG Y. On the climatic uncertainty to the environment extremes: a Singapore case and statistical approach. Polish Journal of Environmental Studies. 24 (3), 1413, 2015.

26. ZHANG Y., CAO Y.Y. A fuzzy quantification approach of uncertainties in an extreme wave height modeling. Acta Oceanologica Sinica, 34(3), 90, 2015.

27. ZHANG Y., JASMINE S.L.L. Estimating the economic losses of port disruption due to extreme wind events. Ocean \& Coastal Management. 116, 300, 2015. 
28. ZHANG Y., MICHAEL B., SER T.Q. Long-term performance assessment and design of offshore structures. Computers \& Structures. 154, 101, 2015.

29. WANG S.P., WANG J.S., ZHANG Q., LI Y.P., WANG Z.L. Applicability evaluation of drought indices in monthly scale drought monitoring in Southwestern and Southern China. Plateau Meteorology. 34 (6), 1616, 2015 [In Chinese].

30. WANG Z.L., WANG J.S., LI Y.H., WANG C.H. Comparision of application between Generalized Extreme Value Index and Standardized Precipitation Index in Northwest China. Plateau Meteorology. 32 (3), 839, 2013 [In Chinese].

31. SVOBODA M., DOUG L.C., HAYES M., HEIM R., GLEASON K., ANGEL J., RIPPEY B., TINKER R., PALECKI M., STOOKSBURY D., MISKUS D., STEPHENS S. The drought monitor. Bull. Amer. Mete. Soc. 8, 1181, 2002.

32. WANG S.P., WANG J.S., ZHANG Q., LI Y.P., WANG Z.L., WANG J. Cumulative Effect of precipitation deficit preceding severe droughts in Southwestern and Southern China. Discrete Dynamics in Nature and Society.
Volume 2016, Article ID 2890852, 10 pages. http://dx.doi. org/10.1155/2016/2890852, 2016.

33. LU E. Determining the start, duration, and strength of flood and drought with daily precipitation: Rationale. Geophys. Res. Lett. 36, L12707, DOI:10.1029/2009GL038817, 2009.

34. ALLEN R.G., PEREIRA L.S., RAES D., SMITH M. Crop evapotranspiration: guidelines for computing crop water requirements. Irrigation and drainage paper. 56, FAO, Rome, 1998.

35. WANG S.P., DUAN H.X., FENG J.Y. Drought situation and its impacts and causes in spring 2011. Journal of Arid Meteorology. 29 (2), 261, 2011 [In Chinese].

36. WANG J.S., WANG S.P., ZHANG Q., LI Y.P., WANG J., ZHANG J. Characteristics of drought disaster-causing factor anomalies in southwestern and southern China against the background of global warming. Polish Journal of Environmental Studies. 24 (5), 2241, 2015.

37. WANG J.S., LI Y.P., REN Y.L., LIU Y.P. Comparison among several drought indices in the Yellow River Valley. Journal of Natural Resources. 28 (8), 1337, 2013 [In Chinese]. 